\title{
STOCHASTIC OPTIMIZATION OF MULTIPLEX CHARGES BASED ON INTERIOR BALLISTICS SIMULATIONS
}

\author{
A. B. Caldeira, \\ T. L. B. Cury, \\ A. L. T. Rezende, \\ and A. V. Gomes \\ Instituto Militar de Engenharia \\ Seção de Engenharia Mecânica e de Materiais \\ 22290-270, Rio de Janeiro, RJ, Brasil \\ aldelio@ime.eb.br \\ Received: July 25, 2017 \\ Revised: October 29, 2017 \\ Accepted: November 30, 2017
}

ABSTRACT

Multiplex charges combine propellant grains with regressive, neutral and progressive burning behaviors in a single propellant charge to improve the interior ballistics. This work optimizes the mass and the web thickness of each type of propellant grain used in a multiplex charge. Two optimization problems are studied: the maximization of the muzzle velocity and the minimization of the maximum pressure inside the gun. Particle Swarm Optimization (PSO) and Differential Evolution (DE) were used to solve the optimization problems. The interior ballistics of a $155 \mathrm{~mm}$ howitzer was simulated by using a lumped parameters model. In this model, the lost energy and the resistance pressure are defined by spline functions based on reference data. The results show that optimized multiplex charges can be used to increase the weapon's utility range and to reduce the weapon's weight.

Keywords: interior ballistics, multiplex charge, optimization, lumped parameter

\section{NOMENCLATURE}

a pressure index of the propellant

B burning rate constant of the propellant

c co-volume

CF DE mutation parameter

CR DE crossover parameter

d caliber

D web thickness

E energy

f web fraction

F propellant impetus

IR inner radius

$\mathrm{k}$ iteration

$\mathrm{m}$ mass

$\mathrm{P}$ gas pressure

Q heat

rand random number

$\mathrm{R}$ constant of the gas

$\mathrm{V}$ velocity of the projectile

Vol volume

$\mathrm{S}$ projectile position

L barrel length

$\mathrm{t}$ time

T gas temperature

$\mathrm{Z}$ propellant form function

$\mathrm{U}$ internal energy of the gas

W projectile kinetic energy

$\mathrm{x}$ particle in the population

$\mathrm{y}$ particle velocity in PSO

\section{Greek symbols}

$\alpha \quad$ PSO inertial parameter

$\beta_{1} \quad$ PSO self-learning parameter

$\beta_{2} \quad$ PSO global learning parameter

$\gamma \quad$ gas specific heats ratio

$$
\begin{array}{ll}
\eta & \text { thermal efficiency } \\
\rho & \text { propellant density }
\end{array}
$$

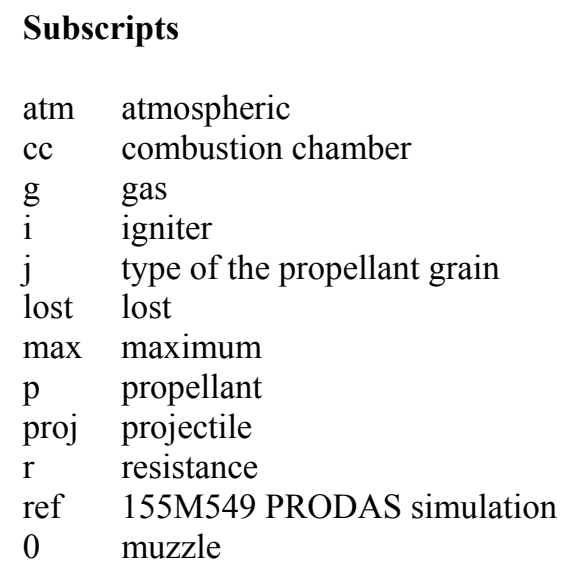

\section{INTRODUCTION}

"A conventional gun is essentially a heat engine in which the propellant contained or injected in the gun chamber is ignited and combusted, transferring its chemical energy into kinetic energy of the projectile" (Maag and Klingenberg, 1996).

The propellant grain geometry influences the gas mass flux supplied by the propellant combustion to impel the projectile. According with the burning area evolution along of the time, the propellant grain is classified as progressive, regressive, or neutral, indicating that the burning area, respectively, increase, decrease or does not change during the burning process (Maag and Klingenberg, 1996, AMCP 706-150, 1965, Farrar and Leeming, 1983, Miner, 2012).

"Multiplex charges consist of two or more different grains of propellants. [...] different grains 
can be made to tailor the pressure-time curve while keeping the maximum pressure within the required limit" (Maag and Klingenberg, 1996).

Experiments with duplex charges (combining two types of grains) and triplex charges (combining three types of grains) have shown the viability of multiplex charges in a rifle 7.62 (Culver, 1972).

Lumped parameters models of the interior ballistics have been used to design: propellants, ammunitions and guns (Cronemberger et al. 2014, AMCP 706-150, 1965, Farrar and Leeming, 1983, Miner, 2012, Baer and Frankle, 1962, Gonzalez, 1990, Li and Zhang, 2011, Cheng and Zhang, 2012, STANAG 4367, 2012, Yildirim, Tiryaki and Kabak, 2012, Sadek et al. 2014). These models have low computational cost, which is relevant in stochastic optimization problems.

Optimizations of propellant charges have been conducted to improve the interior ballistics performance (Gonzalez, 1990, Li and Zhang, 2011, Cheng and Zhang, 2012, STANAG 4367, 2012, Yildirim, Tiryaki and Kabak, 2012, Sadek et al. 2014, Li and Zhang, 2012). These optimizations have been used stochastic methods, as PSO and Genetic Algorithm, and deterministic methods, as Augmented Lagrange Multipliers. The design variables have usually been the web thickness and the propellant mass. Nevertheless, deterrent thickness and other geometric parameters of the propellant grains were also optimized. A duplex charge combining seven perforated and single perforated grains was analyzed (Gonzalez, 1990, Sadek et al. 2014) and a triplex charge with seven perforated, single perforated and chord grains was also studied (Gonzalez, 1990).

The present work is devoted to multiplex charge optimization based on interior ballistics simulations by using stochastic optimization methods. Multiplex charges are optimized, combining propellant grains with different burning behaviors: ball (regressive burning), single perforated (neutral burning) and single perforated with inhibition in the outer surface (progressive burning). The stochastic optimization methods PSO and Differential Evolution (DE) are employed and a Lumped Parameters Model (LPM) is used to simulate the interior ballistics of $155 \mathrm{~mm}$ howitzer.

\section{LUMPED PARAMETERS MODEL (LPM)}

The proposed LPM is based on the projectile dynamics and on the thermodynamics of the gas provided by the propellant burning (Cronemberger et al. 2014, Farrar and Leeming, 1983, Baer and Frankle, 1962).

The propellant burning follows the Robert's law

$$
\frac{\mathrm{df}_{\mathrm{j}}}{\mathrm{dt}}=-\frac{\mathrm{B}}{\mathrm{D}_{\mathrm{j}}} \mathrm{P}^{\mathrm{a}}
$$

where $f$ is the web fraction, $B$ is the burning rate constant, $\mathrm{a}$ is the pressure index, $\mathrm{D}$ is the web thickness and the subscript $\mathrm{j}$ indicates the type of propellant grain.

The propellant form function, $\mathrm{z}_{\mathrm{j}}$, depends on the grain geometry, following

$$
\begin{gathered}
\mathrm{z}_{1}=1-\mathrm{f}_{1}^{3}, \\
\mathrm{z}_{2}=1-\mathrm{f}_{2}, \\
\mathrm{z}_{3}=1-\frac{\left(\mathrm{IR}+\mathrm{D}_{3}\right)^{2}-\left[\mathrm{IR}+\left(1-\mathrm{f}_{3}\right) \mathrm{D}_{3}\right]^{2}}{\left(\mathrm{IR}+\mathrm{D}_{3}\right)^{2}-\mathrm{IR}^{2}} .
\end{gathered}
$$

In Eq.(2-4), $z_{1}$ is the form function of the ball grain (regressive burning grain), $z_{2}$ is the form function of the single perforated grain (neutral burning grain), $z_{3}$ is the form function of the single perforated grain with inhibition in the outer surface (progressive burning grain) and IR is the inner radius of the progressive burning grain.

Therefore, the total mass of gas supplied by propellant burning is

$$
\mathrm{m}_{\mathrm{g}}=\sum \mathrm{m}_{\mathrm{p}, \mathrm{j}} \mathrm{z}_{\mathrm{j}}
$$

where $m_{p, j}$ is the initial mass of the propellant grain of type $\mathrm{j}$.

The Nobel-Abel equation of state is

$$
\mathrm{P}\left(\mathrm{Vol}_{\mathrm{g}}-\mathrm{m}_{\mathrm{g}} \mathrm{c}\right)=\mathrm{m}_{\mathrm{g}} \mathrm{R} \mathrm{T}
$$

$\mathrm{c}, \mathrm{Vol}_{\mathrm{g}}, \mathrm{R}, \mathrm{m}_{\mathrm{g}}$ and $\mathrm{T}$ are, respectively, the co-volume, the volume, the constant, the mass and the absolute temperature of the gas (Maag and Klingenberg, 1996, Cronemberger et al. 2014, AMCP 706-150, 1965, Farrar and Leeming, 1983, Miner, 2012, Baer and Frankle, 1962, Gonzalez, 1990).

The $1^{\text {st }}$ law of the thermodynamics follows

$$
\begin{gathered}
\mathrm{Q}=\Delta \mathrm{U}+\mathrm{W}+\mathrm{E}_{\text {lost }}, \\
\mathrm{Q}=\frac{\mathrm{m}_{\mathrm{g}} \mathrm{F}}{\gamma-1}+\mathrm{E}_{\mathrm{i}}, \\
\mathrm{W}=0.5 \mathrm{~m}_{\text {proj }} \mathrm{V}^{2}, \\
\Delta \mathrm{U}=\frac{\mathrm{P}}{\gamma-1}\left(\mathrm{Vol}_{\mathrm{g}}-\mathrm{m}_{\mathrm{g}} \mathrm{c}\right) .
\end{gathered}
$$

The heat released by igniter and propellant burning, Q, is changed into the projectile kinetic energy, $W$, into the variation of the gas internal energy, $\Delta \mathrm{U}$, and into lost energy, $\mathrm{E}_{\text {lost }}$. 
In these equations, $\mathrm{F}$ is the propellant impetus, $\gamma$ is the gas specific heats ratio, $E_{i}$ is the igniter energy and $\mathrm{m}_{\text {proj }}$ is the projectile mass.

To evaluate the gas volume, it is necessary to consider the initial gas volume in the combustion chamber, the projectile movement and the propellant burning. The volume of gas is

$$
\mathrm{Vol}_{\mathrm{g}}=\mathrm{Vol}_{\mathrm{cc}}-\frac{\mathrm{m}_{\mathrm{p}}}{\rho}+\pi \frac{\mathrm{d}^{2}}{4} \mathrm{~S}+\frac{\mathrm{m}_{\mathrm{g}}}{\rho}
$$

where $\rho$ is the propellant density.

The pressure function follows

$$
\mathrm{P}=\frac{(\gamma-1)\left(\mathrm{Q}-\mathrm{W}-\mathrm{E}_{\text {lost }}\right)}{\mathrm{Vol}_{\mathrm{g}}-\mathrm{m}_{\mathrm{g}} \mathrm{c}} .
$$

The translational dynamics of the projectile is described by the Newton's $2^{\text {nd }}$ law,

$$
\mathrm{m}_{\text {proj }} \frac{\mathrm{dV}}{\mathrm{dt}}=\pi \frac{\mathrm{d}^{2}}{4}\left(\mathrm{P}-\mathrm{P}_{\mathrm{atm}}-\mathrm{P}_{\mathrm{r}}\right)
$$

The atmospheric pressure, $\mathrm{P}_{\mathrm{atm}}$, and the resistance pressure, $\mathrm{P}_{\mathrm{r}}$, act against the projectile movement.

The projectile velocity definition is

$$
\frac{\mathrm{dS}}{\mathrm{dt}}=\mathrm{V} \text {. }
$$

Special attention should be devoted to $\mathrm{P}_{\mathrm{r}}$ and $\mathrm{E}_{\text {lost }}$ modelling, since they cannot be directly measured. In the present model, $\mathrm{P}_{\mathrm{r}}$ and $\mathrm{E}_{\text {lost }}$ are spline functions of the projectile velocity furnished by the interior ballistics simulation of the $155 \mathrm{~mm}$ howitzer performed with the commercial software PRODAS by using 155M549 input data of the PRODAS library. This simulation furnishes discrete values of $\mathrm{P}_{\mathrm{r}}$, but not $\mathrm{E}_{\text {lost }}$ data. Then, the PRODAS output data are introduced in Eq. (7) to compute discrete values of $E_{\text {lost }}$. In sequence, splines (by using interp1 SciLab function) are applied on these discrete values of $E_{\text {lost }}$ and $\mathrm{V}$, defining the $\mathrm{E}_{\text {lost }}$ function. The same procedure is applied on $\mathrm{P}_{\mathrm{r}}$ and $\mathrm{V}$, defining the $\mathrm{P}_{\mathrm{r}}$ function.

A Runge-Kutta fourth order method is implemented in SciLab to solve the system of Eqs.(1), (13) and (14). The initial conditions of the problem are $\mathrm{f}_{\mathrm{j}}=1, \mathrm{~V}=0$ and $\mathrm{S}=0$. The initial pressure is equal to the atmospheric pressure and the initial volume fraction of the burned propellant is null.

\section{M549 SIMULATIONS}

Simulations of a howitzer 155 with M549 ammunition (155M549) were performed by using
PRODAS and LPM, whose input data are shown in Tab. 1.

The form function in the 155M549 LPM simulation follows

$$
z=(1-f)(1+0.12 f)
$$

representing a seven-perforated grain (Farrar and Leeming, 1983).

Table 2 summarizes the output data of the simulations performed by PRODAS and LPM. In this table, $\mathrm{P}_{\max }$ is the maximum pressure, $\mathrm{P}_{0}$ is the muzzle pressure, $t_{0}$ is the total time of the interior ballistics, $\mathrm{V}_{0}$ is the projectile muzzle velocity and $\eta$ is the thermal efficiency of the weapon, which can be computed by

$$
\eta=\frac{0.5 \mathrm{~m}_{\text {proj }} \mathrm{V}_{0}^{2}}{\frac{\mathrm{F} \sum \mathrm{m}_{\mathrm{p}, \mathrm{j}}}{\gamma-1}+\mathrm{E}_{\mathrm{i}}}
$$

Table 1. 155M549 input data.

\begin{tabular}{|c|c|}
\hline PARAMETER & VALUE \\
\hline Igniter energy $\left(\mathrm{E}_{\mathrm{i}}\right)$ & $375745.8 \mathrm{~J}$ \\
\hline Mass of propellant $\left(\mathrm{m}_{\mathrm{p}}\right)$ & $11.7934 \mathrm{~kg}$ \\
\hline Impetus of the propellant $(\mathrm{F})$ & $1.09 \mathrm{MJ} / \mathrm{kg}$ \\
\hline $\begin{array}{c}\text { Ratio of specific heats of the } \\
\text { gas }(\gamma)\end{array}$ & 1.25 \\
\hline Co-volume $(\mathrm{c})$ & $1.057510^{-3} \mathrm{~m}^{3} / \mathrm{kg}$ \\
\hline Propellant grain & seven perforated \\
\hline Density of the propellant $(\rho)$ & $1660.8 \mathrm{~kg} / \mathrm{m}^{3}$ \\
\hline $\begin{array}{c}\text { Pressure index of the } \\
\text { propellant }(\mathrm{a})\end{array}$ & 0.67 \\
\hline $\begin{array}{c}\text { Burning rate constant of the } \\
\text { propellant }(\mathrm{B})\end{array}$ & $5.4210^{-7}(\mathrm{~m} / \mathrm{s}) \mathrm{Pa}^{-\mathrm{a}}$ \\
\hline Web thickness $(\mathrm{D})$ & $2.0015 \mathrm{~mm}$ \\
\hline Mass of projectile $\left(\mathrm{m}_{\text {proj }}\right)$ & $43.5448 \mathrm{~kg}$ \\
\hline Projectile diameter $\left(\mathrm{d}_{\text {proj }}\right)$ & $155 \mathrm{~mm}$ \\
\hline Barrel length $(\mathrm{L})$ & $5.08 \mathrm{~m}$ \\
\hline $\begin{array}{c}\text { Volume of the } \\
\text { combustion chamber }\left(\mathrm{Vol}_{\mathrm{cc}}\right)\end{array}$ & $0.01886 \mathrm{~m}^{3}$ \\
\hline
\end{tabular}

Tab. 2 reveals the congruence of LPM and PRODAS simulations.

Table 2. 155M549 output data.

\begin{tabular}{|c|c|c|c|c|c|}
\hline Method & $\eta$ & $\begin{array}{c}\mathrm{P}_{\max } \\
(\mathrm{MPa})\end{array}$ & $\begin{array}{c}\mathrm{P}_{0} \\
(\mathrm{MPa})\end{array}$ & $\begin{array}{c}\mathrm{t}_{0} \\
(\mathrm{~ms})\end{array}$ & $\begin{array}{c}\mathrm{V}_{0} \\
(\mathrm{~m} / \mathrm{s})\end{array}$ \\
\hline PRODAS & 0.29 & 278.8 & 82 & 24 & 826 \\
\hline LPM & 0.28 & 279.7 & 82 & 24 & 823 \\
\hline
\end{tabular}

\section{OPTIMIZATION PROBLEMS} follow

The interior ballistics optimization problems

$$
\text { Minimize } g\left(D_{j}, m_{p, j}\right) \text {, }
$$


subject to $0.5 \mathrm{~mm} \leq \mathrm{D}_{\mathrm{j}} \leq 3 \mathrm{~mm}$,

$$
0 \mathrm{~kg} \leq \mathrm{m}_{\mathrm{p}, 1} \leq 7 \mathrm{~kg}
$$

$$
0 \mathrm{~kg} \leq \mathrm{m}_{\mathrm{p}, 2} \leq 11.7934 \mathrm{~kg}
$$

$0 \mathrm{~kg} \leq \mathrm{m}_{\mathrm{p}, 3} \leq 16 \mathrm{~kg}$,

$$
\sum \mathrm{m}_{\mathrm{p}, \mathrm{j}} \leq 31 \mathrm{~kg}
$$

$$
\mathrm{P} \leq \mathrm{P}_{\text {max }, \text { ref }},
$$

$$
\mathrm{V}_{0} \geq \mathrm{V}_{0, \text { ref }}
$$

where the subscript ref indicates the data of the PRODAS simulation in Tab. 2.

The box constraints limits in Eq.(19-21) were chosen to avoid $\mathrm{P}>\mathrm{P}_{\text {max,ref }}$, considering the cases with a single type of propellant grain, and the inequality limit value in Eq.(22), considering the maximum capacity of the combustion chamber.

The $1^{\text {st }}$ optimization problem $\left(1^{\text {st }}\right.$ OP $)$ maximizes the muzzle velocity,

$$
\begin{aligned}
& \mathrm{g}\left(\mathrm{D}_{\mathrm{j},}, \mathrm{m}_{\mathrm{p}, \mathrm{j}}\right)=\mathrm{V}_{0}^{-1}+ \\
& +10^{2}\left|\mathrm{P}_{\max }-\mathrm{P}_{\text {max }, \text { ref }}\right| \operatorname{step}\left(\mathrm{P}_{\text {max,ref }}\right)
\end{aligned}
$$

and the $2^{\text {nd }}$ optimization problem $\left(2^{\text {nd }} \mathrm{OP}\right)$ minimizes the maximum pressure,

$$
\begin{aligned}
& g\left(D_{j}, m_{p, j}\right)=\frac{P_{\max }}{P_{\text {max,ref }}}+ \\
& +10^{2}\left|V_{0}-V_{0, \text { ref }}\right|\left[\operatorname{step}(0)-\operatorname{step}\left(V_{0, \text { ref }}\right)\right]
\end{aligned}
$$

In Eq.(25) and (26) step is the unit step function and the second term of these equations are penalty functions. In Eq.(25), the penalty function prevent maximum pressures greater than the $155 \mathrm{M} 549$ one (Tab. 2) and, in Eq.(26), the penalty function keep the muzzle velocity greater than the 155M549 one (Tab. 2).

\section{STHOCASTIC OPTIMIZATION METHODS}

To solve the optimization problems two methods are employed: Particle Swarm Optimization (PSO) and Differential Evolution (DE). In both methods, the initial population of possible solutions is created inside the feasible domain and each possible solution of the population is called particle.

PSO is based on a flock of birds looking for food (Cheng and Zhang, 2012, Sadek et al. 2014, Colaço et al. 2006) and the evolution rules of the particles can be written as

$$
\begin{gathered}
y_{n}^{k+1}=\alpha y_{n}^{k}+\beta_{1} \operatorname{rand}_{1, n}\left(x_{b, n}^{k}-x_{n}^{k}\right)+ \\
+\beta_{2} \operatorname{rand}_{2, n}\left(x_{b g}^{k}-x_{n}^{k}\right) \\
x_{n}^{k+1}=x_{n}^{k}+y_{n}^{k} .
\end{gathered}
$$

where $\mathrm{x}$ is a particle, $\mathrm{y}$ is the particle velocity, $\operatorname{rand}_{1, \mathrm{n}}$ and $\operatorname{rand}_{2, \mathrm{n}}$ are random numbers with normal distribution in the range from 0 to 1 , the subscript $b$ indicates the best value of the particle $n$ along its history and the subscript bg indicates the best particle of the population. Moreover, $\mathrm{k}$ is the iteration. In PSO, $\alpha, \beta_{1}$ and $\beta_{2}$ are arbitrary values and, in this study, they are, respectively, equal to $0.5,0.7$ and 1.25 .

DE is based on the Darwin's Theory of Evolution (Colaço et al. 2006). During the population evolution mutations and chromosome crossover occur. The evolution rule is

$$
\begin{gathered}
\mathrm{x}_{\mathrm{n}}^{\mathrm{k}+1}=\delta_{1} \mathrm{x}_{\mathrm{n}}^{\mathrm{k}}+\delta_{2}\left[\mathrm{x}_{\mathrm{bg}}^{\mathrm{k}}+\mathrm{CF}\left(\mathrm{x}_{\mathrm{r} 1}^{\mathrm{k}}-\mathrm{x}_{\mathrm{r} 2}^{\mathrm{k}}\right)\right], \\
\delta_{1}=\left\{\begin{array}{l}
0, \text { if } \operatorname{rand}_{1, \mathrm{n}}^{\mathrm{k}}<\mathrm{CR} \\
1, \text { if } \operatorname{rand}_{1, \mathrm{n}}^{\mathrm{k}} \geq \mathrm{CR}
\end{array},\right. \\
\delta_{2}=\left\{\begin{array}{l}
1, \text { if } \operatorname{rand}_{1, \mathrm{n}}^{\mathrm{k}}<\mathrm{CR} \\
0, \text { if } \operatorname{rand}_{1, \mathrm{n}}^{\mathrm{k}} \geq \mathrm{CR}
\end{array}\right.
\end{gathered}
$$

It takes into account the best particle of the population and two particles $\mathrm{x}_{\mathrm{r} 1}$ and $\mathrm{x}_{\mathrm{r} 2}$, which are randomly chosen within the population. $\mathrm{CR}$ and $\mathrm{CF}$ are arbitrary parameters in the range from 0.5 to 1.0 , which control crossover and mutation processes. In this work, $\mathrm{CR}=0.5$ and $\mathrm{CF}=0.5$.

During the population evolution, particles can fall outside the feasible domain. Thus, repair procedures must put these particles inside the feasible domain (Helwig, 2010). If a box constraint is not satisfied, the particle is put on nearest constraint limit and if Eq.(22) is not satisfied, the particle is discharged and a new particle in the feasible domain is randomly created (Helwig, 2010).

The stopping criterion establishes that

$$
\left|\frac{g\left(D_{j}^{k}, m_{p, j}^{k}\right)-g\left(D_{j}^{k-1}, m_{p, j}^{k-1}\right)}{g\left(D_{j}^{k-1}, m_{p, j}^{k-1}\right)}\right| \leq 0.01,
$$

must be satisfied during 50 consecutive iterations.

\section{RESULTS}

The PRODAS simulation, reported in Tab. 2, is the reference curve in Fig. 1 to 6 . In these figures, optimized propellant charges results computed with 
PSO and DE, considering populations with 20 and 40 particles, are shown.

Solutions for $1^{\text {st }}$ optimization problem are presented in Fig. 1 to 3 .

Fig. 1 reports the pressure inside the weapon along the projectile travel position. It is important to note that increasing the area below the $\mathrm{P} \times \mathrm{S}$ curve, the work and the muzzle velocity increase.

The effect of the population size is more relevant on DE results than on PSO ones. Moreover, the PSO have increased more the area below $\mathrm{P} \times \mathrm{S}$ curve than DE.

Fig. 2 shows the projectile velocity along the projectile travel position. In this figure, it is observed that the highest muzzle velocity was obtained by using PSO with 40 particles in the population. However, every optimized charge has improved the muzzle velocity in relation to the reference case.

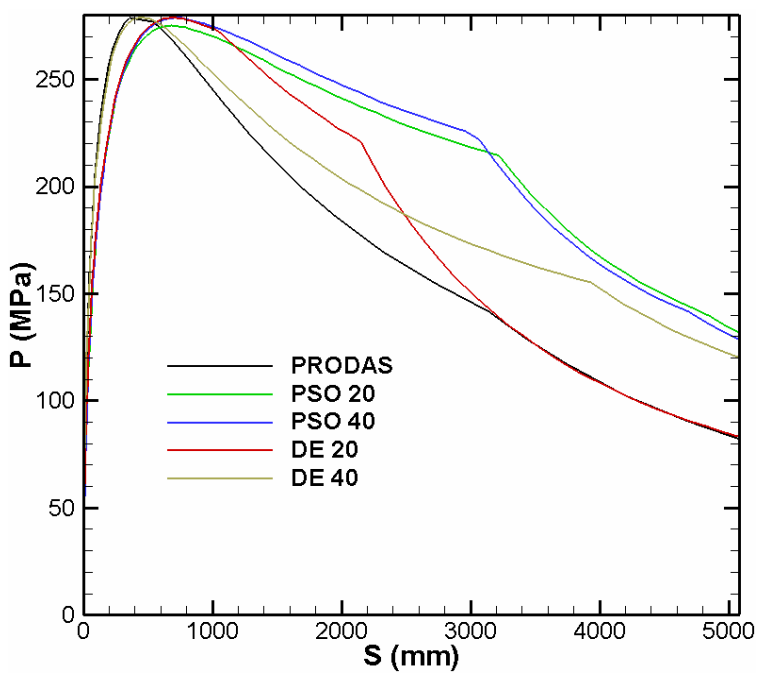

Figure 1. Pressure inside the howitzer $\left(1^{\text {st }} \mathrm{OP}\right)$.

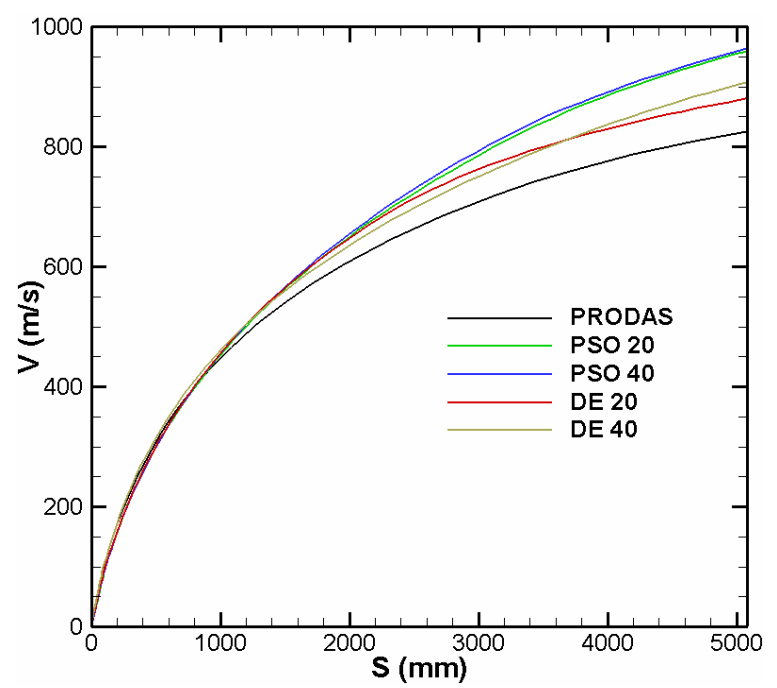

Figure 2. Projectile velocity $\left(1^{\text {st }} \mathrm{OP}\right)$.

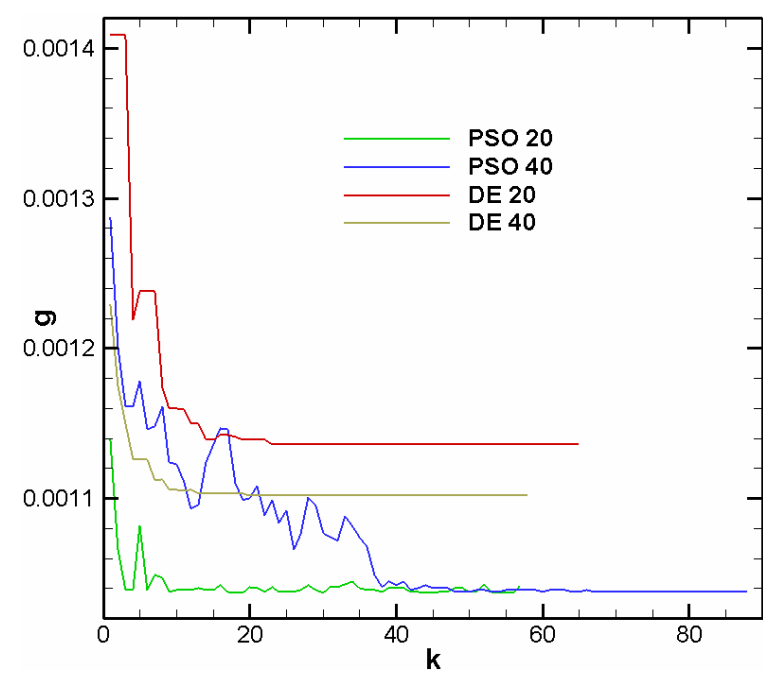

Figure 3. Objective function evolution $\left(1^{\text {st }} \mathrm{OP}\right)$.

Fig. 3 depicts the objective function evolution along of the iterations. PSO have minimized more the objective function than DE. Otherwise, PSO with 40 particles in the population have spent more iterations to converge.

Table 3 summarizes the $1^{\text {st }}$ optimization problem results. The results reveal that optimized charges have large amount of progressive burning grains. Nevertheless, small quantities of regressive and neutral burning grains can significantly change the muzzle velocity. Moreover, PSO 40 is the best choice to improve the muzzle velocity. The PSO 40 muzzle velocity is $17 \%$ greater than the PRODAS muzzle velocity. Besides, PSO 40 has the same thermal efficiency value of the reference case (Tab. 2).

Table 3. Summary of $1^{\text {st }}$ OP results.

\begin{tabular}{|c|c|c|c|c|}
\hline Method & \multicolumn{2}{|c|}{ PSO } & \multicolumn{2}{c|}{ DE } \\
\hline Population & 20 & 40 & 20 & 40 \\
\hline$\eta$ & 0.28 & 0.29 & 0.31 & 0.26 \\
\hline $\mathrm{k}$ & 57 & 88 & 65 & 58 \\
\hline $\mathrm{V}_{0}(\mathrm{~m} / \mathrm{s})$ & 960 & 963 & 880 & 907 \\
\hline $\mathrm{P}_{\max }(\mathrm{MPa})$ & 275.1 & 278.8 & 278.8 & 278.8 \\
\hline $\mathrm{m}_{\mathrm{p}, 1}(\mathrm{~kg})$ & 0.000 & 0.008 & 0.309 & 1.502 \\
\hline $\mathrm{m}_{\mathrm{p}, 2}(\mathrm{~kg})$ & 0.358 & 0.051 & 1.697 & 2.758 \\
\hline $\mathrm{m}_{\mathrm{p}, 3}(\mathrm{~kg})$ & 16.000 & 16.000 & 10.197 & 11.428 \\
\hline $\mathrm{D}_{1}(\mathrm{~m})$ & 0.0013 & 0.0028 & 0.0025 & 0.0028 \\
\hline $\mathrm{D}_{2}(\mathrm{~m})$ & 0.0029 & 0.0021 & 0.0013 & 0.0026 \\
\hline $\mathrm{D}_{3}(\mathrm{~m})$ & 0.0020 & 0.0020 & 0.0017 & 0.0021 \\
\hline
\end{tabular}

The DE 20 case (Tab. 3) provided the worst optimized muzzle velocity, but the best thermal efficiency. Therefore, it is possible to improve the thermal efficiency with optimized multiplex charges.

Results of the $2^{\text {nd }}$ optimization problem are presented in Fig. 4, 5 and 6 and in Tab 4. These figures are, respectively, analogous to Fig. 1, 2 and 3. 


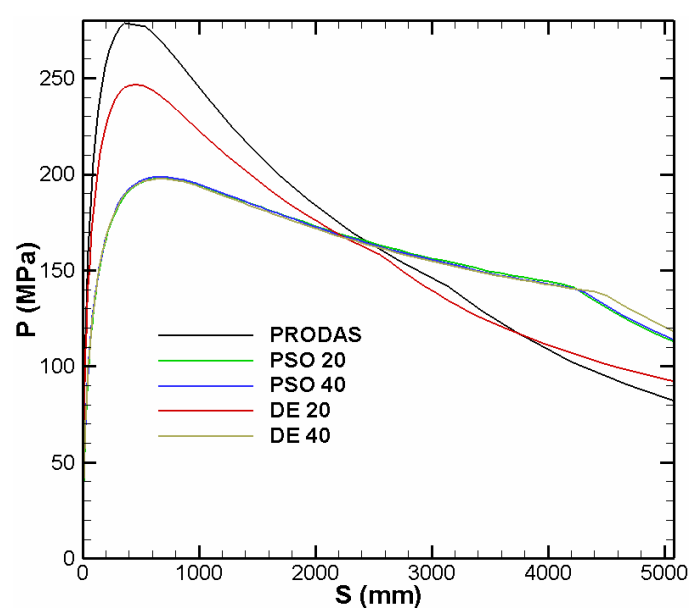

Figure 4. Pressure inside the howitzer $\left(2^{\text {nd }} O P\right)$.

Fig. 4 and 5 shows that PSO 20, PSO 40 and DE 40 have almost the same maximum pressure and projectile velocity curve.

The evolution of the objective function in Fig. 6 shows that DE 20 is the worst optimized solution. Nevertheless, DE 40 is the best solution, reaching the lowest value for the objective function and spending less iterations to converge.

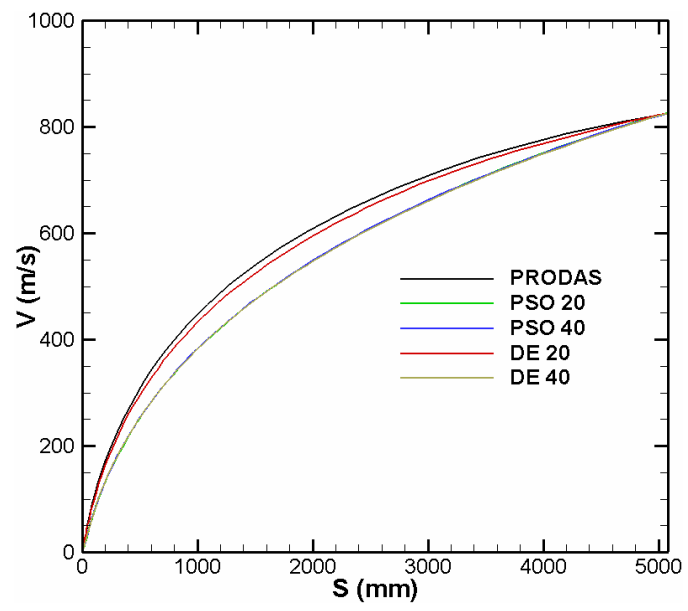

Figure 5. Projectile velocity $\left(2^{\text {nd }} O P\right)$.

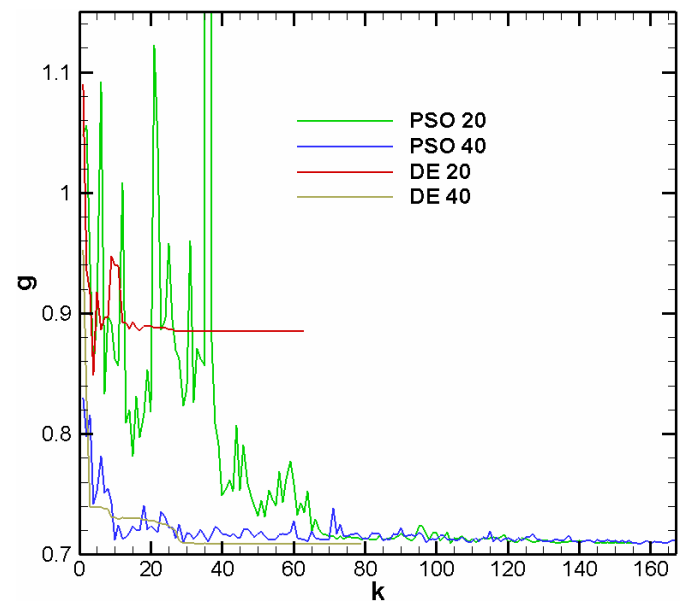

Figure 6. Objective function evolution $\left(2^{\text {nd }} \mathrm{OP}\right)$.
Table 4. Summary of $2^{\text {nd }}$ OP results.

\begin{tabular}{|c|c|c|c|c|}
\hline Method & \multicolumn{2}{|c|}{ PSO } & \multicolumn{2}{c|}{$\mathrm{DE}$} \\
\hline Population & 20 & 40 & 20 & 40 \\
\hline$\eta$ & 0.24 & 0.23 & 0.26 & 0.23 \\
\hline $\mathrm{k}$ & 155 & 167 & 63 & 79 \\
\hline $\mathrm{V}_{0}(\mathrm{~m} / \mathrm{s})$ & 826 & 826 & 826 & 826 \\
\hline $\mathrm{P}_{\max }(\mathrm{MPa})$ & 197.8 & 198.6 & 246.7 & 197.6 \\
\hline $\mathrm{m}_{\mathrm{p}, 1}(\mathrm{~kg})$ & 0.004 & 0.026 & 0.000 & 0.000 \\
\hline $\mathrm{m}_{\mathrm{p}, 2}(\mathrm{~kg})$ & 0.006 & 0.066 & 6.455 & 0.000 \\
\hline $\mathrm{m}_{\mathrm{p}, 3}(\mathrm{~kg})$ & 14.383 & 14.369 & 6.725 & 14.829 \\
\hline $\mathrm{D}_{1}(\mathrm{~m})$ & 0.0007 & 0.0019 & 0.0010 & 0.0005 \\
\hline $\mathrm{D}_{2}(\mathrm{~m})$ & 0.0030 & 0.0015 & 0.0017 & 0.0011 \\
\hline $\mathrm{D}_{3}(\mathrm{~m})$ & 0.0022 & 0.0022 & 0.0023 & 0.0023 \\
\hline
\end{tabular}

Table 4 summarizes the results for the $2^{\text {nd }}$ optimization problem. The thermal efficiencies reported in Tab. 4 are worse than reference case thermal efficiency (Tab. 2), but the same muzzle velocity is attained. Moreover, DE 40 maximum pressure is $29 \%$ lower than reference case maximum pressure. Noteworthy that DE 40 propellant charge has only progressive grains.

\section{CONCLUSION}

The present LPM has proposed an alternative approach to evaluate the resistance pressure and the lost energy, employing output data of PRODAS simulation. The congruence between LPM and PRODAS simulations has shown that such alternative approach is a promising procedure.

The results of optimized propellant charges have shown that large amounts of progressive burning grains should be used in multiplex charges. In this sense, single perforated grains with inhibition in the outer surface were useful to increase the muzzle velocity and to minimize the maximum pressure. Moreover, small amounts of regressive and neutral propellants grains are relevant to increase the powder load density, being useful to increase the muzzle velocity. On the other hand, regressive and neutral grains should be avoided to reduce the maximum pressure inside the gun.

Increasing the muzzle velocity, the utility range of the weapon is also increased and reducing the maximum pressure of the interior ballistics, lighter weapons could be designed, improving the mobility.

Particle Swarm and Differential Evolution were effective to solve the optimization problems. Though, PSO results were better than DE ones, maximizing the muzzle velocity, and DE results were better than PSO ones, minimizing the maximum pressure.

The size of populations in the studied stochastic methods has influenced the optimized results. The quality of the results was improved, when the population size was increased. However, the effects of the population size on PSO results were less relevant than on $\mathrm{DE}$ ones. 


\section{REFERENCES}

AMCP 706-150, 1965, Engineering Design Handbook, Ballistics Series, Interior Ballistics of Guns.

Baer, P. G., and Frankle, J. M., 1962, The Simulation of Interior Ballistics of Guns by Digital Computer Program, Ballistic Research Laboratories, Aberdeen Proving Ground, Maryland, USA. Report No 1183.

Cheng, C., and Zhang, X., 2012, Interior Ballistic Charge Design Based on a Modified Particle Swarm Optimizer, Structural and Multidisciplinary Optimization, Vol. 46, No. 2, 303-310.

Colaço, M. J., Orlande, H. R. B., and Dullikravich, G. S., 2006, Inverse and Optimization Problems in Heat Transfer, Journal of the Brazilian Society of Mechanical Sciences and Engineering, Vol. 28, No. 1, pp. 1-24.

Cronemberger, P. O., Lima Júnior, E. P., Gois, J. A. M., and Caldeira, A. B., 2014, Theoretical and Experimental Study of the Interior Ballistics of a Rifle 7.62, Engenharia Térmica (Thermal Engineering), Vol. 13, No. 2, pp. 20-27.

Culver, R., O., 1972, Velocity and Pressure Effects on Projectiles due to Variation of Ignition Parameters, Master Thesis, Naval Postgraduate School, Monterey, CA, USA.

Farrar, C. L., and Leeming, D. W., 1983, Military Ballistics: a Basic Manual, Brassey's Battlefield Weapon System and Technology, Vol. X, Brassey's Defense Publisher, England, 214 p.

Gonzalez, J., R., 1990, Interior Ballistics Optimization, Master Thesis, Kansas State University, Manhattan, KS, USA.

Helwig, S., 2010, Particle Swarms for Constrained Optimization, Doctoral Thesis, Technischen Fakultät der Universität ErlangenNürnberg, Erlangen, Bavaria, Germany.

Li, K., and Zhang, X., 2012, Using NSGA-II and TOPSIS Methods for Interior Ballistic Optimization Based on One-Dimensional Two-Phase Flow Model. Propellants Explosives and Pyrotechnics, Vol. 37, No.4, pp. 468-475.

Li, K., and Zhang, X., 2011, Multi-Objective Optimization of Interior Ballistic Performance Using NSGA-II, Propellants Explosives and Pyrotechnics, Vol. 36, No. 3, pp. 282-290.

Maag, H. -J., and Klingenberg, G., 1996, Gun Propulsion Concepts. Part II: Solid and Liquid Propellants, Propellants, Explosives, Pyrotechnics, Vol. 21, No. 1, pp. 1-7.

Miner, R., T., 2012, Computational Interior Ballistics Modeling, Master Thesis, University of New Mexico, Albuquerque, NM, USA.

Sadek, H. E., Zhang, X., Rashad, M., and Cheng, C., 2014, Improvement of Interior Ballistic Performance Utilizing Particle Swarm Optimization, Mathematical Problems in Engineering, Article ID 156103, 10 pages. doi: 10.1155/2014/156103
STANAG 4367, 2012, Thermodynamic Interior Ballistic Model with Global Parameters, NATO.

Yildirim, F., Tiryaki, E., and Kabak, M., 2012, Optimal Propellant Grain Geometry Design for Large Caliber Projectiles, in: Proceedings: 5th International Scientific Conference on Defense Technology, Belgrade, Serbia. 